\title{
Subcellular transcriptome alterations in a cell culture model of spinal muscular atrophy point to widespread defects in axonal growth and presynaptic differentiation
}

\author{
LENA SAAL, ${ }^{1,3}$ MICHAEL BRIESE, ${ }^{1,3}$ SUSANNE KNEITZ, ${ }^{2}$ MICHAEL GLINKA, ${ }^{1}$ and MICHAEL SENDTNER ${ }^{1}$ \\ ${ }^{1}$ Institute for Clinical Neurobiology, University of Wuerzburg, D 97078 Wuerzburg, Germany \\ ${ }^{2}$ Department of Physiological Chemistry I, Biocenter, University of Wuerzburg, D 97074 Wuerzburg, Germany
}

\begin{abstract}
Neuronal function critically depends on coordinated subcellular distribution of mRNAs. Disturbed mRNA processing and axonal transport has been found in spinal muscular atrophy and could be causative for dysfunction and degeneration of motoneurons. Despite the advances made in characterizing the transport mechanisms of several axonal mRNAs, an unbiased approach to identify the axonal repertoire of mRNAs in healthy and degenerating motoneurons has been lacking. Here we used compartmentalized microfluidic chambers to investigate the somatodendritic and axonal mRNA content of cultured motoneurons by microarray analysis. In axons, transcripts related to protein synthesis and energy production were enriched relative to the somatodendritic compartment. Knockdown of Smn, the protein deficient in spinal muscular atrophy, produced a large number of transcript alterations in both compartments. Transcripts related to immune functions, including MHC class I genes, and with roles in RNA splicing were up-regulated in the somatodendritic compartment. On the axonal side, transcripts associated with axon growth and synaptic activity were down-regulated. These alterations provide evidence that subcellular localization of transcripts with axonal functions as well as regulation of specific transcripts with nonautonomous functions is disturbed in Smn-deficient motoneurons, most likely contributing to the pathophysiology of spinal muscular atrophy.
\end{abstract}

Keywords: motoneuron; axon; compartment; spinal muscular atrophy

\section{INTRODUCTION}

Mechanisms regulating subcellular mRNA distribution play an important role for localized protein synthesis in distinct subcellular compartments. In Drosophila embryos, $>70 \%$ of all transcripts appear regionally distributed (Lecuyer et al. 2007). The preciseness of the transport mechanisms underlying mRNA dispersion is particularly important for highly polarized cells such as neurons (Lin and Holt 2008). Among these, motoneurons are exceptional in that their axons navigate and bridge extensive distances from the somatodendritic part in the spinal cord to their target muscle. In addition, motoneurons have up to several thousand axonal terminals that form synapses with muscle fibers, requiring a highly regulated subcellular transport of proteins and mRNAs that contribute to synaptic plasticity and function.

Muscle paralysis in motoneuron diseases such as spinal muscular atrophy (SMA) and amyotrophic lateral sclerosis (ALS) is caused by functional impairment and degeneration of motoneurons. To date, significant advances have been

\footnotetext{
${ }^{3}$ These authors contributed equally to this work.

Corresponding author: Sendtner_M@ukw.de

Article published online ahead of print. Article and publication date are at http://www.rnajournal.org/cgi/doi/10.1261/rna.047373.114.
}

made in identifying causative genes and elucidating functions of their protein products. Still, it is currently unknown why motoneurons appear more vulnerable than other types of neurons to gene defects in SMN1, SOD1, TDP-43, FUS, or C9orf72, and how these gene defects lead to synaptic dysfunction at neuromuscular endplates. Patients with SMA, the most common form of motoneuron disease in children and young adults, have reduced levels of the survival motor neuron $(\mathrm{SMN})$ protein due to deletion or mutations in the SMN1 gene (Lefebvre et al. 1995). SMN interacts with a large number of proteins and is involved in multiple aspects of RNA processing (Kolb et al. 2007; Burghes and Beattie 2009; Li et al. 2014). The most thoroughly described function for SMN is its role in the generation of spliceosomal small nuclear ribonucleoprotein particles (snRNPs) mediating intron excision (Battle et al. 2006). In complex with specific proteins, Gemins2-8 and unrip, SMN mediates the formation of the seven-membered Sm core domain of uridine-

(C) 2014 Saal et al. This article is distributed exclusively by the RNA Society for the first 12 months after the full-issue publication date (see http:// rnajournal.cshlp.org/site/misc/terms.xhtml). After 12 months, it is available under a Creative Commons License (Attribution-NonCommercial 4.0 International), as described at http://creativecommons.org/licenses/by-nc/4.0/. 
rich spliceosomal snRNPs (Fischer et al. 1997; Liu et al. 1997; Chari et al. 2008). Indeed, alterations in the snRNP repertoire as a consequence of reduced Smn levels have already been reported (Gabanella et al. 2007; Zhang et al. 2008) and there is also evidence that such alterations contribute to altered pre-mRNA splicing over time (Zhang et al. 2008; Lotti et al. 2012). However, to what extent such splicing defects are directly caused by Smn loss or are secondary effects as a response to cellular dysfunction remains to be determined (Baumer et al. 2009; Garcia et al. 2013).

Further hypotheses on the etiology of SMA have emerged by (i) the observation that the SMN protein is localized in axons of motoneurons (Zhang et al. 2003) and (ii) the identification of a number of RNA-binding proteins interacting with SMN such as hnRNP R and Q (Rossoll et al. 2002), FMRP (Piazzon et al. 2008), HuD (Fallini et al. 2011), IMP1 (Fallini et al. 2013) as well as TDP-43 (Wang et al. 2002; Tsuiji et al. 2013), and FUS (Yamazaki et al. 2012). The latter two are implicated in ALS. Thus, in addition to its integral function in snRNP biogenesis, SMN, as part of RNP granules, might regulate mRNA processing and subcellular transport into axons and growth cones. In SMA, impaired axonal delivery of mRNAs due to SMN loss could constitute an additional defect contributing to the selective degeneration of motoneurons. In support of this "axonal hypothesis" of SMA, Smn knockdown in primary motoneurons impairs axonal levels of poly(A)-mRNA in general, indicating a widespread RNA transport defect (Fallini et al. 2011). Even though previous studies have already revealed $\beta$-actin mRNA as one such candidate being reduced in Smn-deficient motor axons (Rossoll et al. 2003; Glinka et al. 2010), an unbiased approach to identify misregulated axonal mRNAs has not been made so far. As axonal defects including defective spontaneous firing (Jablonka et al. 2007), defective axon outgrowth (McWhorter et al. 2003), and impaired neurotransmission at neuromuscular junctions in both mouse models (Kariya et al. 2008; McGovern et al. 2008; Murray et al. 2008; Kong et al. 2009) and patients (Mishra et al. 2004; Swoboda et al. 2005) are a prominent pathological feature in SMA, such an approach might provide insights into the molecular deficiencies underlying these perturbations.

Compartmentalized chambers have been widely used to selectively extract axonal RNA in order to investigate the axonal mRNA composition of sympathetic and sensory dorsal root ganglion (DRG) neurons (Hengst et al. 2009; Vogelaar et al. 2009; Andreassi et al. 2010; Gumy et al. 2011). However, while these types of neurons exhibit rapid axon outgrowth with axon lengths reaching $>1 \mathrm{~cm}$ after $4 \mathrm{~d}$ in culture (Gumy et al. 2011), axons of primary motoneurons grow at a more moderate pace and require up to $7 \mathrm{~d}$ to reach lengths typically $<1 \mathrm{~mm}$ (Wiese et al. 2010). Thus, motoneurons require optimized culturing conditions to obtain sufficient RNA from the axonal compartment for transcriptome analysis. We used primary embryonic mouse motoneurons that were cultured for $7 \mathrm{~d}$ in compartmentalized microfluidic chambers and investigated the somatodendritic and axonal mRNA repertoire using linear amplification and microarray hybridization. In axons of wild-type motoneurons we found an enrichment of transcripts related to protein synthesis, energy production, and RNA binding relative to the somatodendritic part. When Smn was knocked down in compartmentalized motoneurons, the mRNA content changed in both the somatodendritic and the axonal compartments. Strikingly, most transcripts that were changed on the somatodendritic side of Smn knockdown motoneurons were upregulated. Among these were transcripts associated with roles in RNA splicing and immune functions. In contrast, transcripts on the axonal side appeared mostly down-regulated relative to the controls and were mainly implicated in axon growth. Thus, our data indicate that Smn deficiency affects the subcellular transcriptome in both the somatodendritic and axonal regions of motoneurons impairing transcripts with selected functions. These alterations could be responsible for specific defects in axons that lead to synaptic dysfunction and axonal degeneration in spinal muscular atrophy.

\section{RESULTS}

\section{Compartmentalized motoneuron cultures enable selective extraction of somatodendritic and axonal RNA for microarray analysis}

In order to investigate transcriptome alterations in axonal and somatodendritic compartments of Smn-deficient motoneurons in an unbiased manner, we optimized conditions for culturing motoneurons in compartmentalized microfluidic chambers (Fig. 1A; Hengst et al. 2009). Thereby, 1 million motoneurons were plated into one compartment of a microfluidic chamber and a gradient of the neurotrophic factor BDNF was used to direct axonal outgrowth into the other compartment. After $7 \mathrm{~d}$ in vitro (DIV) these primary motoneurons appeared fully differentiated (Fig. 1B). A dense network of axonal processes was visualized by Tau immunostaining and many of these Tau-positive axonal processes had grown into the axonal compartment (Fig. 1B). At that stage, characteristic spontaneous action potentials have been observed in these cells and presynaptic terminals develop clusters of voltage-gated calcium channels characteristic of presynaptic active zones (Jablonka et al. 2007). RNA was isolated after 7 DIV from the somatodendritic and the axonal compartment of cultured wild-type motoneurons as well as control and Smn knockdown motoneurons (described below) and linearly amplified for two rounds. During each round mRNA was reverse transcribed by a T7 sequence-containing primer followed by second-strand synthesis of the cDNA and in vitro transcription to obtain antisense RNA. The amplified RNA was labeled and hybridized to a 3' IVT Affymetrix Gene Chip Mouse Genome 4302.0 Array.

Resulting signal intensities were normalized by quantile normalization (Bolstad et al. 2003) and logarithmized. Genes 
A
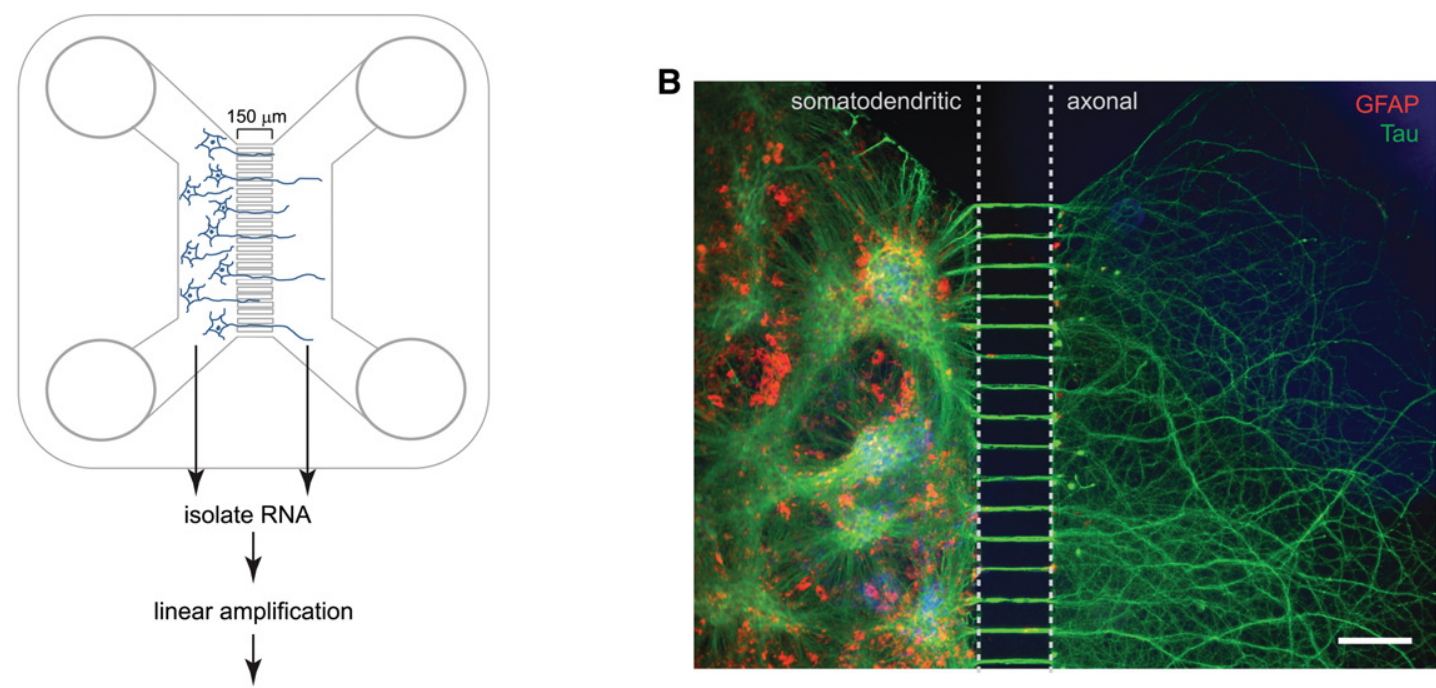

microarray hybridization

C
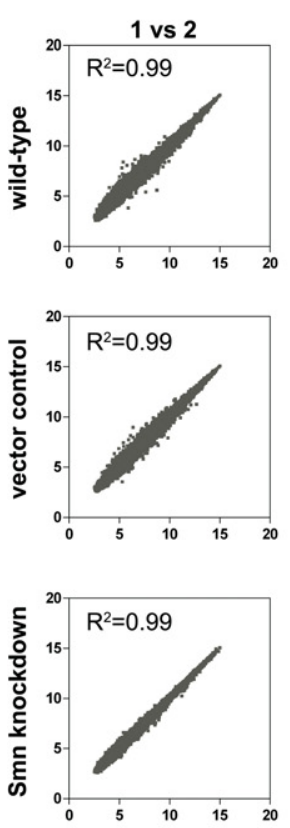

somatodendritic
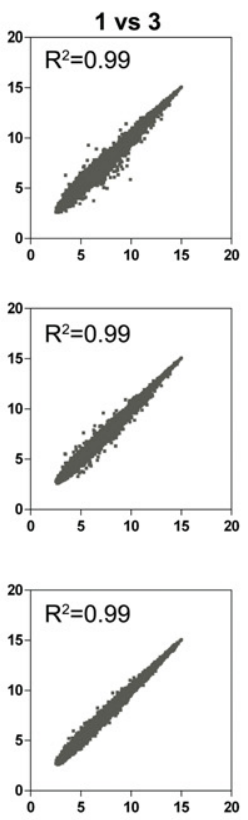
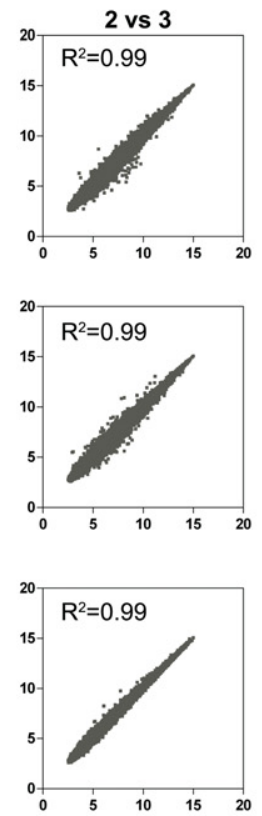
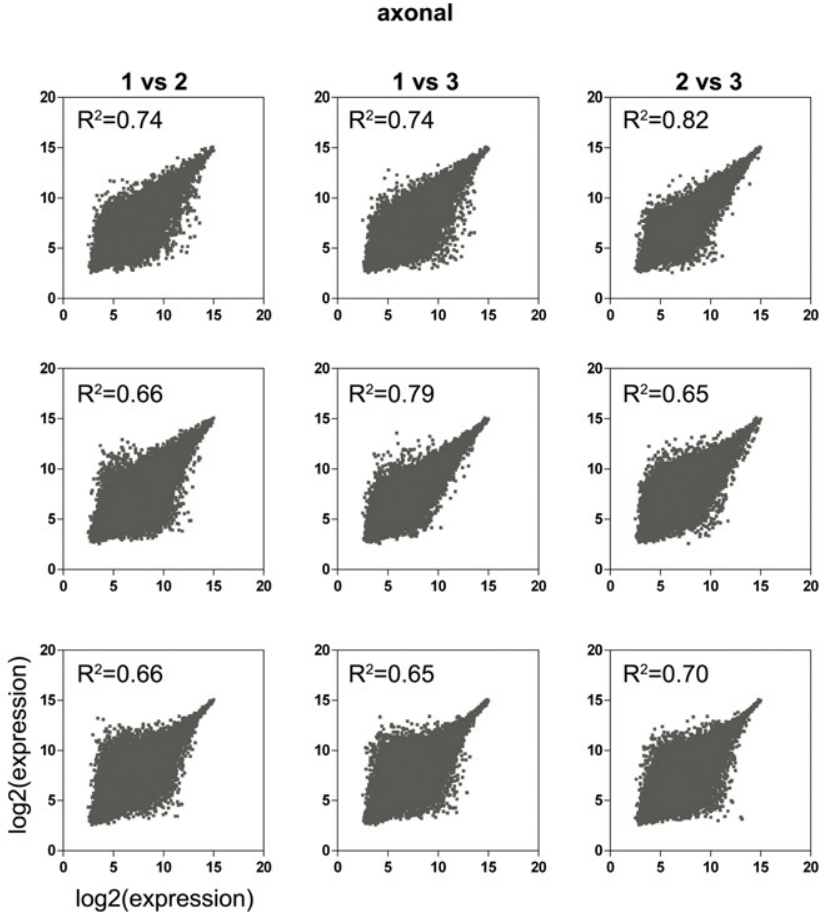
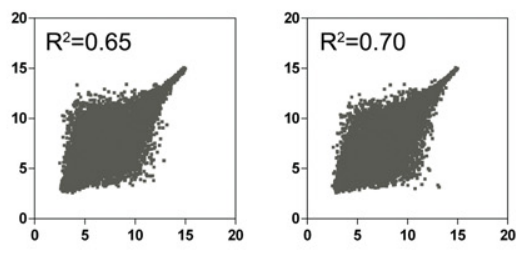

FIGURE 1. Compartmentalized motoneuron cultures for microarray analysis of somatodendritic and axonal RNA. (A) Schematic of a microfluidic chamber in which primary motoneurons (E12.5) cultured on the left (somatodendritic) side extend axons through 150- $\mu \mathrm{m}$-long microgrooves to the right (axonal) side. (B) Immunofluorescence staining for Tau (green) showing a dense network of axonal processes on the right side of the microfluidic chamber. Nuclear staining with DAPI (blue) and immunofluorescence staining for GFAP (red) shows the complete absence of somata on the axonal side. Scale bar: $150 \mu \mathrm{m}$. (C) Reproducibility of microarray data.

differentially expressed in Smn knockdown motoneurons compared with wild-type and control motoneurons were selected by the bioconductor package Limma (Smyth 2004). Quantile normalization assumes changes in expression to be roughly equal in both directions. However, for the axonal compartment we observed a strong down-regulation of a large number of transcripts. To avoid any bias, normalization and differential expression analysis was conducted separately for the somatodendritic (Supplemental Table S1) and the axonal compartment (Supplemental Table S2). Following normalization, expression values for each of the 45,101 probesets were highly reproducible among the individual replicates from the somatodendritic compartments $\left(R^{2}=0.99\right.$ for all comparisons) (Fig. 1C). The expression values for the individual axonal replicates were more variable $\left(R^{2}=0.65-\right.$ 0.82 ) due to the low amount of RNA that could be extracted 
from the axonal compartments (Fig. 1C). The degree of correlation for individual probesets of the axonal data sets was dependent on their signal intensities. Probesets with low expression values correlated less between replicates than probesets detecting highly expressed transcripts.

\section{Motor axons are enriched for transcripts involved in protein synthesis, energy production, and RNA binding}

In order to gain insights into the mRNA composition of motor axons in general, we first compared the axonal microarray data sets with their respective somatodendritic counterparts for each of three independent wild-type motoneuron compartmentalized cultures (Fig. 2A). The correlation between axonal and somatodendritic microarray data was robust with the correlation coefficient $R^{2}$ being in the range of 0.71-0.8 (Fig. 2A). Next, we examined the axonal transcriptome of wild-type motoneurons by investigating functions associated with the top 5000 ranked probesets using gene ontology (GO) term analysis (Fig. 2B; Supplemental Table S3). Likewise, we obtained GO terms enriched among the top 5000 somatodendritic transcripts (Fig. 2B; Supplemental Table S4). We also analyzed the bottom 5000 ranked probesets for each compartment as a control for the specificity of our data sets (Fig. 2B; Supplemental Tables S5, S6). Among the top 5000 ranked probesets 3764 (75.3\%) were shared between the somatodendritic and the axonal compartments. This overlap is reflected by the similarity of GO terms enriched for each compartment. The most significant GO terms were related to translation, protein transport, energy production, and RNA binding (Fig. 2B). In contrast, GO terms associated with the bottom-ranked probesets showed much less significance and were related, i.e., to pheromone response and plasma membrane localization. Notably, the level of significance for a number of GO terms enriched among the top-ranked probesets was much higher for the axonal than for the somatodendritic compartment (Fig. 2B). Therefore, we selected all GO terms common to both compartments to compare their significance (Fig. 2C; Supplemental Table S7). For each of the three ontologies "biological process," "cellular component," and "molecular function" GO terms related to protein synthesis ("translation," "ribosome," "structural constituent of ribosome"), energy metabolism ("generation of precursor metabolites and energy," "electron transport chain," "mitochondrion"), and RNA binding ("ribonucleoprotein complex," "RNA binding") were more significantly enriched in the axonal compared with the somatodendritic compartment. Notably, while the GO term "growth cone" (cellular component) was more significant in the axonal compartment as expected, the GO term "synapse" was more significantly enriched in the somatodendritic compartment (Fig. 2C; Supplemental Table S7). As the GO term "synapse" also includes postsynaptic components its enrichment in the somatodendritic compared with the axonal compartment is due to the presence of postsynaptic structures on dendrites, the latter being more abundant than proximal axons and thus contributing more RNA than axons. Other GO terms enriched on the somatodendritic side related to synaptic functions include "regulation of neurotransmitter levels" and "synaptic transmission" (Supplemental Table S7).

\section{Smn knockdown in motoneurons affects a vast number of somatodendritic mRNAs}

Next, we investigated changes in the somatodendritic and axonal mRNA repertoire upon Smn depletion. As it was not feasible to isolate 1 million motoneurons from embryos from the $S m n^{-1}$;SMN2tg SMA mouse model (Monani et al. 2000), Smn transcript levels were suppressed by lentiviral shRNA knockdown producing a reduction by $>90 \%$ (Fig. $3 \mathrm{~A}$ ). As reference data sets, we used motoneurons transfected with the empty lentiviral expression vector as well as the wildtype motoneurons described above. The correlation of the individual replicate data sets for the Smn knockdown motoneurons and empty vector controls was comparable with those of wild-type motoneurons (Fig. 1C). Differential expression analysis of the microarray data revealed substantial changes in transcript abundance in both the somatodendritic (Fig. 3B) as well as the axonal compartment (Fig. 3C) upon Smn depletion. On the somatodendritic side 2058 probesets were changed significantly $(P<0.05)$. The top 50 most significantly deregulated probesets were all up-regulated (Fig. 3D). Among these, transcripts with roles in the interferon pathway such as Stat1, Gbp3, and Usp18 were substantially increased (Fig. 3D).

Of the 2058 transcript alterations in the somatodendritic compartment, 856 probesets were down-regulated after depletion of the Smn protein (Supplemental Table S8). Among these, GO term analysis revealed an enrichment of transcripts associated with nuclear functions such as cell division (Fig. 4A; Supplemental Table S9). In contrast, the 1202 probesets up-regulated in the somatodendritic compartment upon Smn loss (Supplemental Table S10) showed an enrichment for genes with cytosolic functions including roles in translation, protein localization, and RNA binding (Fig. 4A; Supplemental Table S11). Moreover, we detected transcripts involved in RNA splicing to be up-regulated such as the spliceosomal components $S f 1, S f 3 b 3$, and U2af1, as well as the splicing regulators $S f r s 1, T r a 2 b$, and Celf2 (Fig. 4B; Supplemental Table S11). Transcripts encoding components of the major histocompatibility complex I (MHC class I) including the $\beta_{2}$-microglobulin transcript were also increased in Smn knockdown motoneurons (Fig. $4 \mathrm{~A}, \mathrm{~B})$. These transcripts were absent in control motoneurons transfected with an empty lentiviral construct indicating that up-regulation of MHC class I components is a consequence of Smn loss rather than viral delivery of the knockdown construct. 
A
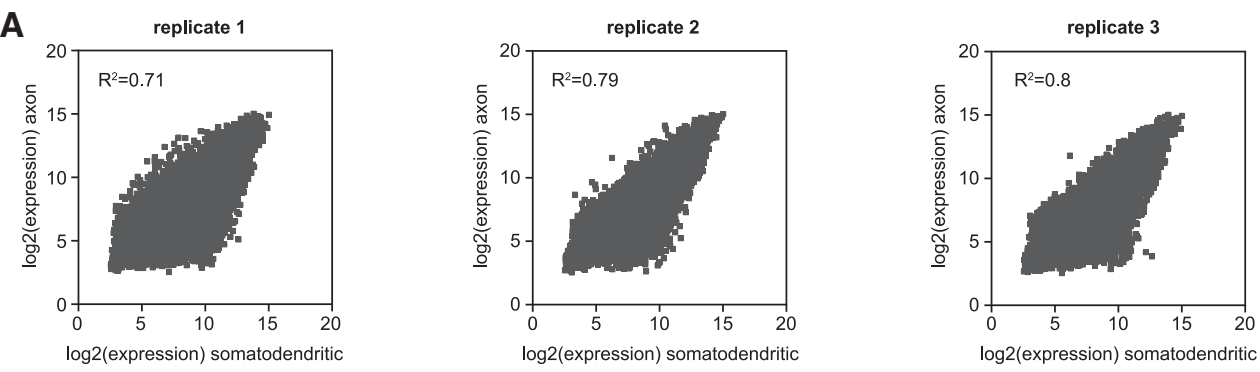

B $\log 2$ (expression) somatodendritic

$\log 2$ (expression) somatodendritic
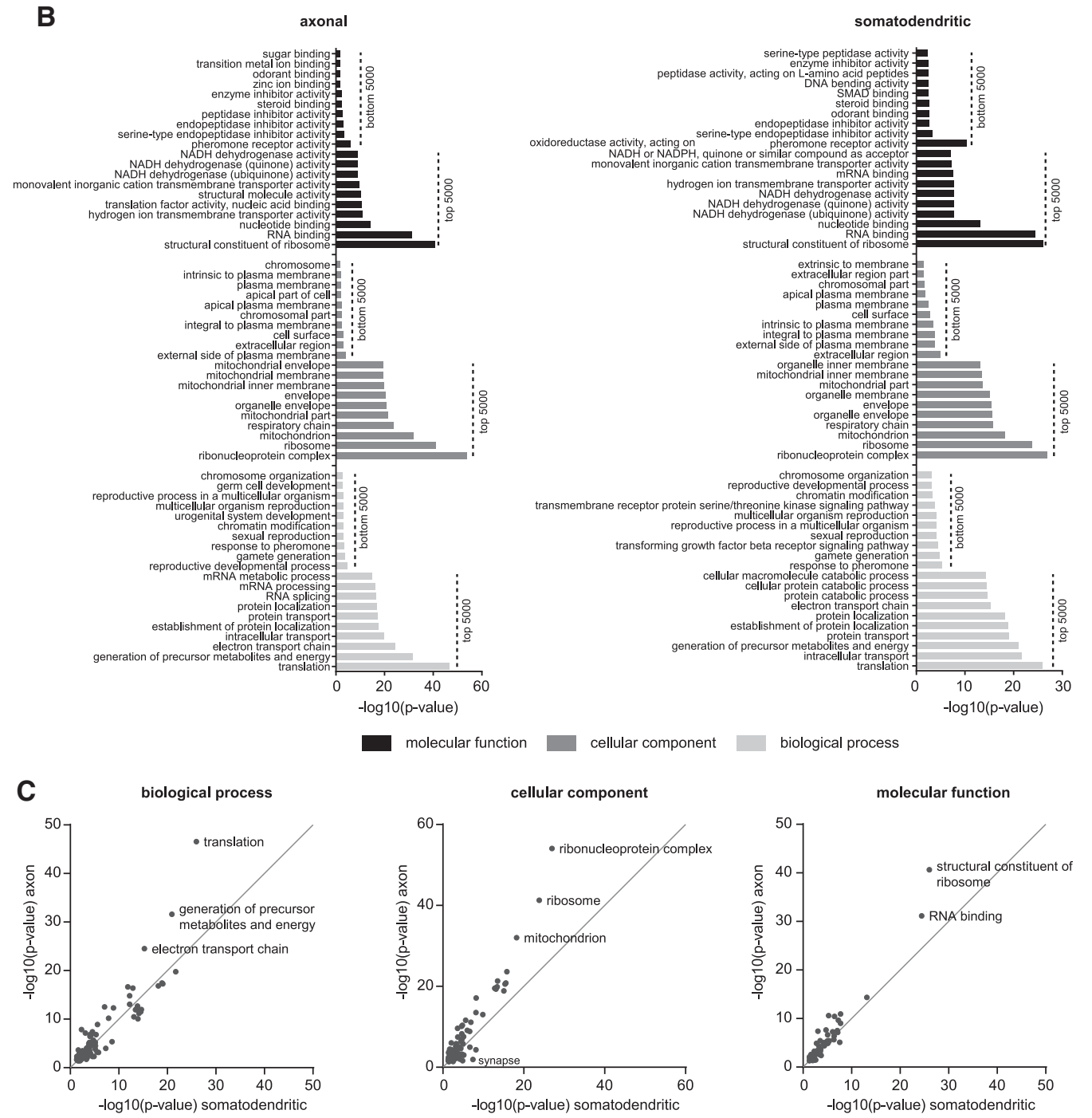

FIGURE 2. GO term analysis of genes expressed in the somatodendritic and axonal compartment of cultured wild-type motoneurons. (A) Correlation of axonal with somatodendritic microarray expression values for the three replicate wild-type motoneuron compartmentalized chambers. (B) GO terms enriched among the top 5000 expressed and bottom 5000 expressed somatodendritic and axonal transcripts. (C) Scatter plots depicting the enrichment of GO terms common to the top 5000 expressed somatodendritic and axonal transcripts for the different ontologies.

Recently, a number of transcriptome changes were detected in laser-captured motoneurons of presymptomatic $S m n^{-1-} ; S M N 2^{+/+} ; S M N \Delta 7^{+/+}$mice by deep RNA sequencing (Zhang et al. 2013). Of the 138 genes reported in that study as up-regulated in affected motoneurons, seven were present in our set of transcripts increased in the somatodendritic compartments of Smn-deficient motoneurons: BC006779, Crip2, Enc1, Cd68, Slc39a7, Mageh1, and C1qb (Table 1). Similarly, of the 110 down-regulated genes, eight were found in our data set of transcripts decreased in the somatodendritic compartment of Smn-deficient motoneurons: Kcnab1, Etv1, Palld, Chrdl1, Sgpp2, Osgepl1, Gdnf, and Abi3bp (Table 1). 
A
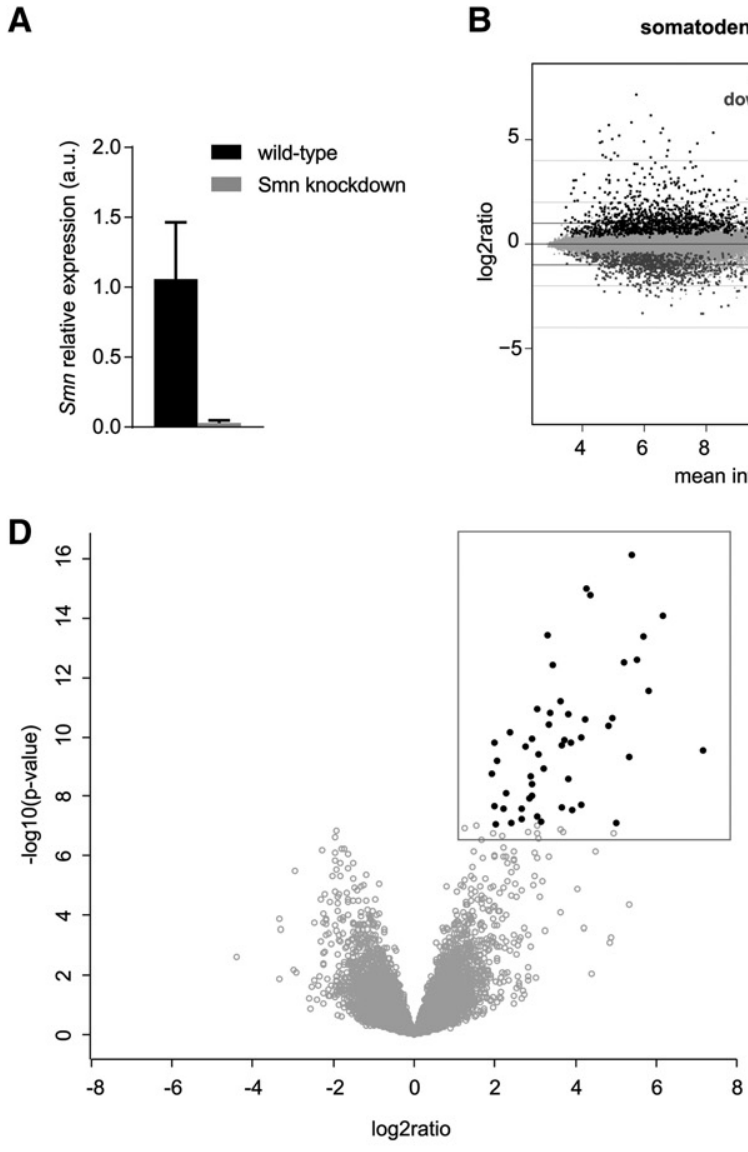

E

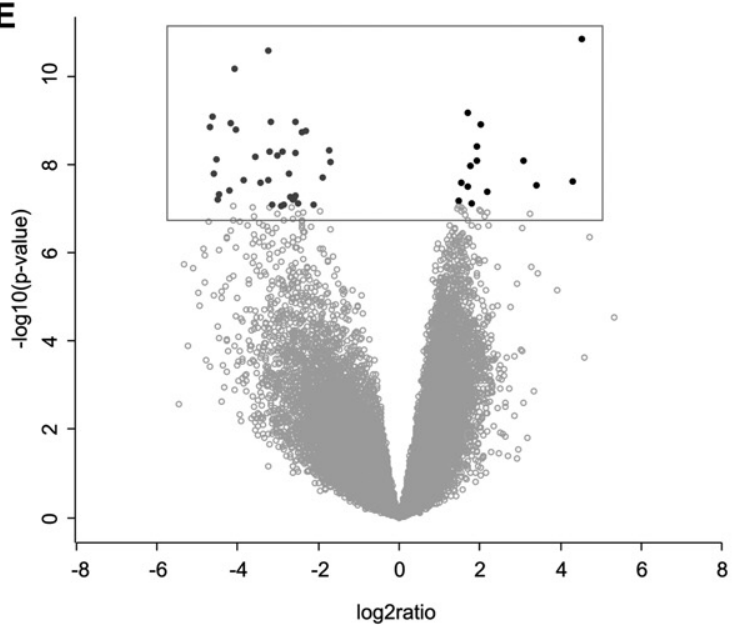

B

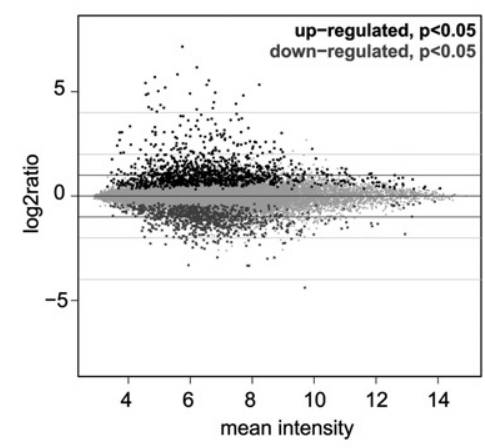

C

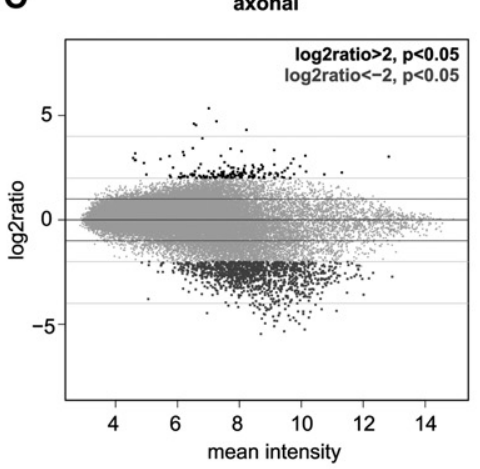

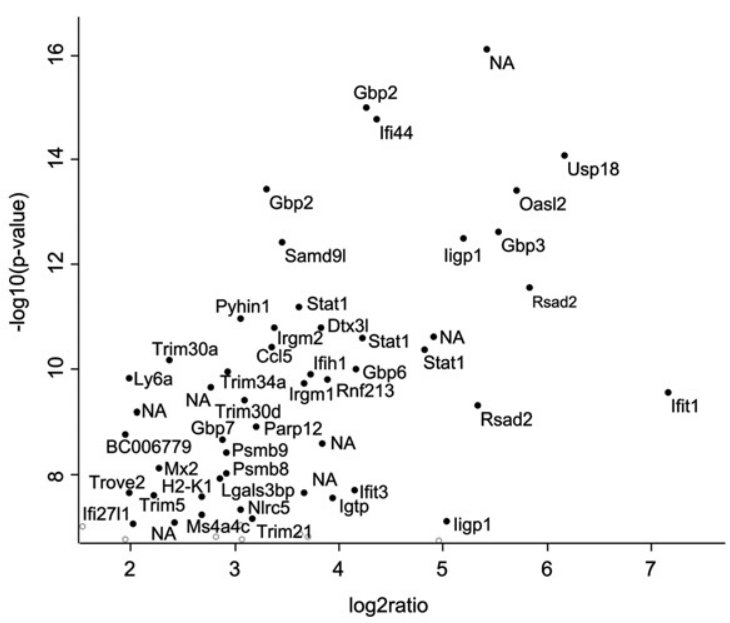

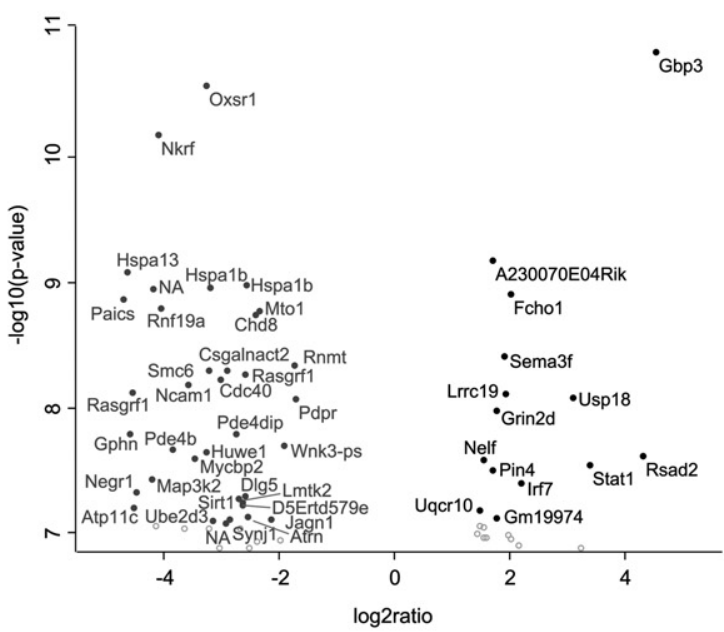

FIGURE 3. Transcript level changes in compartmentalized cultures of Smn-deficient motoneurons. (A) Smn transcript levels in wild-type and Smn knockdown motoneurons measured by quantitative PCR (qPCR). RNA was linearly amplified for one round prior to qPCR analysis. (B) MA plots of Smn knockdown microarray data from the somatodendritic compartment showing the relationship between the change in gene expression ( $\log _{2}$ ratio) upon Smn knockdown relative to wild-type and GFP-expressing controls and the average level of gene expression (mean intensity) for each microarray probeset. Significantly up-regulated (black) and down-regulated (dark gray) transcripts are indicated. (C) MA plots of microarray data from axonal compartments. For axonal transcript changes an additional cutoff of $\mid \log _{2}$ ratio $\mid>2$ was applied. $(D)$ Volcano plot of Smn knockdown microarray data for somatodendritic compartments indicating the significance of change in gene expression $\left[-\log _{10}(P)\right]$ for each probeset relative to the magnitude of change ( $\log _{2}$ ratio). The top 50 most significantly deregulated genes are marked by filled circles. The magnified boxed area is shown on the right. (E) Volcano plot for axonal microarray data. In $D$ and $E$, up-regulated genes are shown in black and down-regulated genes are shown in dark gray. 
A

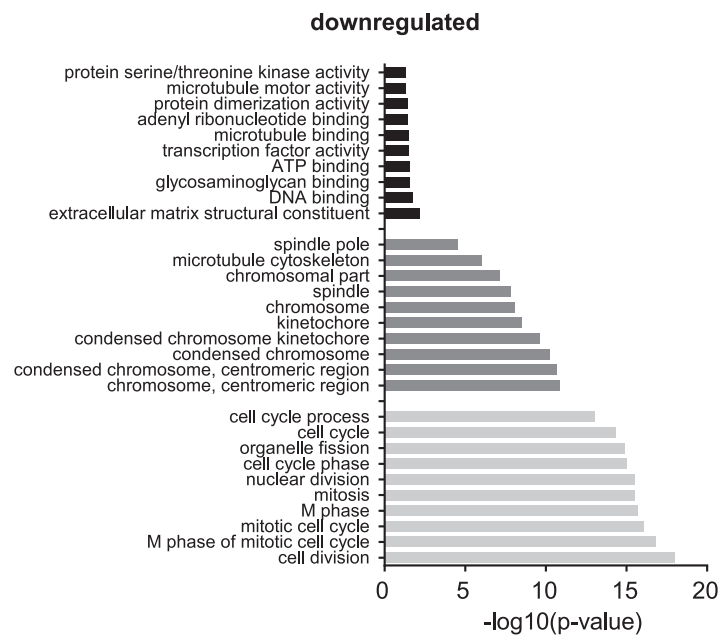

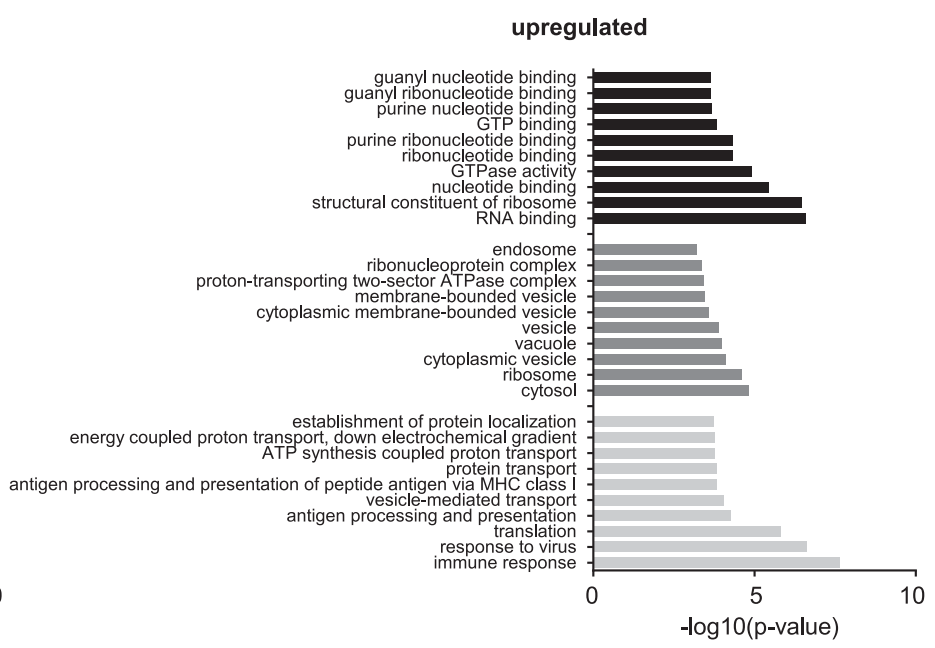

cellular component $\quad$ biological process

B

\begin{tabular}{|c|c|}
\hline AffymetrixIDs & Gene name \\
\hline 1450743_s_at & synaptotagmin binding, cytoplasmic RNA interacting protein \\
\hline 1417135_at & serine/arginine-rich protein specific kinase 2 \\
\hline 1422769_at & synaptotagmin binding, cytoplasmic RNA interacting protein \\
\hline 1431044_at & THO complex 1 \\
\hline 1418573_a_at & hnRNP-associated with lethal yellow \\
\hline 1418245_a_at & RNA binding protein, fox- 1 homolog (C. elegans) 2 \\
\hline 1430982_at & serine/arginine-rich splicing factor 1 \\
\hline 1460633_at & PRP19/PSO4 pre-mRNA processing factor 19 homolog (S. cerevisiae) \\
\hline 1422509_at & U2 small nuclear ribonucleoprotein auxiliary factor (U2AF) 1 \\
\hline 1423971_at & THO complex 3 \\
\hline 1439777_at & CUGBP, Elav-like family member 2 \\
\hline 1437322_at & RNA binding motif protein 4 \\
\hline 1454798_at & RNA binding motif protein $15 \mathrm{~B}$ \\
\hline 1429748_at & RIKEN CDNA B930003M22 gene \\
\hline 1417136_s_at & serine/arginine-rich protein specific kinase 2 \\
\hline 1441466_at & transformer 2 beta homolog (Drosophila) \\
\hline 1423895_a_at & CUGBP, Elav-like family member 2 \\
\hline 1423750_a_at & splicing factor 1 \\
\hline 1420934_a_at & serine/arginine repetitive matrix 1 \\
\hline 1430075_at & splicing factor $3 b$, subunit 3 \\
\hline 1416736_at & cancer susceptibility candidate 3 \\
\hline 1428171_at & PRP39 pre-mRNA processing factor $39 \mathrm{~h}$ \\
\hline
\end{tabular}

FIGURE 4. GO term analysis of transcripts deregulated in the somatodendritic compartment of Smn knockdown motoneurons. (A) The top 10 GO categories for "biological process," "cellular component," and "molecular function" for transcripts down-regulated or up-regulated upon Smn knockdown relative to controls $(P<0.05)$. $(B)$ Transcripts in the GO category "RNA splicing" and "antigen processing and presentation of peptide antigen via MHC class I" up-regulated as a result of Smn knockdown.

\section{Smn deficiency reduces the availability of synaptic transcripts in motor axons}

While transcriptional changes in the somatodendritic compartment occurred in both directions, we detected mostly down-regulated transcripts in the axonal compartment of Smn knockdown motoneurons (Fig. 3C,E). Using a $P$-value $<0.05$ and fold change $>4$ as threshold, we detected changes for 1354 probesets. Of these, 1189 probesets were down-regulated (Supplemental Table S12), compared with only 165 probesets being up-regulated (Supplemental Table S13). In the set of transcripts down-regulated in Smn-deficient motor axons, mRNAs associated with synaptic localization were overrepresented (Fig. 5A; Supplemental Table S14) including genes with known synaptic functions such as Piccolo, Synapsin II, Cyfip1 and 2, and the mRNA coding for Neurofilament-M chain. In contrast, transcripts up-regulated in axons of Smn knockdown motoneurons functionally match those up-regulated in the somatodendritic compartment. These transcripts are either implicated in translation such as the ribosomal proteins $\mathrm{L} 13, \mathrm{~S} 13$, and $\mathrm{S} 9$ and the translation initiation factor Eif3c or in MHC class I antigen presentation (Fig. 5A; Supplemental Table S15).

As our correlation analysis of the individual microarray replicate data sets from the axonal compartments revealed higher levels of variations for low and medium expressed transcripts we focused our analysis on probesets with a mean expression value of $>10$ in the control data sets (wild-type and empty vector). We detected 195 such highly expressed probesets that were changed upon Smn knockdown with a $P$-value $<0.05$ and fold change $>4$ (Fig. 5B; Supplemental Table S16). Only eight of these 195 probesets (detecting the genes Slc25a39, Zfp706, Mettl9, Ank3, Erc2, 
TABLE 1. Subset of transcripts up-regulated or down-regulated in the somatodendritic compartment of Smn-deficient motoneurons that were also detected as up- or down-regulated in laser-microdissected motoneurons from an SMA mouse model in a previous study

\begin{tabular}{|c|c|c|c|c|c|}
\hline Gene name & Symbol & AffymetrixID & Ratio & Fold change & $P$-value \\
\hline \multicolumn{6}{|l|}{ Up-regulated } \\
\hline cDNA sequence BC006779 & BC006779 & 1435454_a_at & 3.84 & 3.84 & $1.78 \times 10^{-9}$ \\
\hline Cysteine rich protein 2 & Crip2 & 1417311_at & 2.07 & 2.07 & $9.96 \times 10^{-5}$ \\
\hline Ectodermal-neural cortex 1 & Enc1 & 1420964_at & 1.59 & 1.59 & $1.88 \times 10^{-2}$ \\
\hline CD68 antigen & Cd68 & 1449164_at & 6.02 & 6.02 & $2.32 \times 10^{-2}$ \\
\hline Solute carrier family 39 (zinc transporter), member 7 & Slc39a7 & 1416949_s_at & 1.93 & 1.93 & $3.43 \times 10^{-2}$ \\
\hline Melanoma antigen, family $\mathrm{H}, 1$ & Mageh1 & 1422498_at & 2.11 & 2.11 & $3.56 \times 10^{-2}$ \\
\hline Complement component 1 , q subcomponent, $\beta$ polypeptide & $\mathrm{C} 1 \mathrm{qb}$ & 1437726_x_at & 6.71 & 6.71 & $4.73 \times 10^{-2}$ \\
\hline \multicolumn{6}{|l|}{ Down-regulated } \\
\hline Sphingosine-1-phosphate phosphotase 2 & Sgpp2 & 1457867_at & 0.40 & 2.47 & $8.47 \times 10^{-5}$ \\
\hline $\mathrm{ABI}$ gene family, member 3 (NESH) binding protein & Abi3bp & 1427054_s_at & 0.60 & 1.67 & $1.18 \times 10^{-3}$ \\
\hline Palladin, cytoskeletal associated protein & Palld & 1433768_at & 0.46 & 2.19 & $7.41 \times 10^{-3}$ \\
\hline Chordin-like 1 & Chrdl1 & 1434201_at & 0.71 & 1.41 & $1.14 \times 10^{-2}$ \\
\hline Glial cell line derived neurotrophic factor & Gdnf & 1419080_at & 0.57 & 1.76 & $2.41 \times 10^{-2}$ \\
\hline Chordin-like 1 & Chrdl1 & 1456722_at & 0.66 & 1.52 & $2.98 \times 10^{-2}$ \\
\hline ets variant gene 1 & Etv1 & 1450684_at & 0.38 & 2.65 & $3.34 \times 10^{-2}$ \\
\hline O-sialoglycoprotein endopeptidase-like 1 & Osgepl1 & 1439715_at & 0.63 & 1.60 & $3.48 \times 10^{-2}$ \\
\hline Potassium voltage-gated channel, shaker-related subfamily, $\beta$ member 1 & Kcnab1 & 1448468_a_at & 0.52 & 1.93 & $4.35 \times 10^{-2}$ \\
\hline
\end{tabular}

For the previous study, see Zhang et al. (2013).

Rbfox1, 2610005L07Rik) also showed a significant change in the somatodendritic compartment of Smn knockdown motoneurons (Fig. 5C). Thus, changes in the axonal transcriptome of Smn-deficient motoneurons are not necessarily dependent on transcript level alterations in the somatodendritic compartment. Among the 195 axonal mRNA alterations, transcripts related to GO terms for neuron projections, axons, and growth cones were significantly downregulated (Fig. 5D; Supplemental Table S17), potentially contributing to defects in axon elongation and presynaptic differentiation previously described for Smn-deficient motoneurons (Rossoll et al. 2003).

In order to validate our microarray predictions we performed quantitative real-time PCR on RNA amplified for one round from somatodendritic and axonal compartments of Smn knockdown and wild-type motoneurons. Transcript level changes detected by microarray in the somatodendritic compartment of Smn knockdown motoneurons were in line with the relative transcript changes detected by qPCR (Fig. 6A). Axonal transcript levels measured by qPCR showed a higher degree of variability (Fig. 6B). This result is in agreement with the variability seen in the microarray replicates from the axonal compartments (Fig. 1C) and is, most likely, the result of technical noise associated with low amounts of input RNA. Nevertheless, we detected reductions in transcript levels for Apc, Dcx, Mettl9, Ank3, Gphn, Cpsf3, and Syn3 in Smn-deficient motor axons. Despite not being polyadenylated, the long noncoding RNA Malat1 was still captured by the RNA amplification procedure and detectable by the microarray. Therefore, we included it in our qPCR analysis and found an up-regulation in both the somatodendritic as well as in the axonal compartment.

\section{Minor intron-containing genes are not overrepresented among transcripts deregulated by Smn knockdown}

In order to determine whether genes containing U12-type introns are overrepresented among the transcripts deregulated in Smn knockdown motoneurons, we used a list of 555 U12type introns from the U12 Intron Database (http://genome. crg.es/datasets/u12/) (Alioto 2007) present in 497 genes. These U12-type intron genes are represented by 827 probesets corresponding to $1.8 \%$ of the total number of probesets $(45,101)$ present on the array. Among the 2058 probesets with significant changes on the somatodendritic side of compartmentalized Smn knockdown motoneurons, 37 probesets matched U12-type genes corresponding to $1.8 \%$. Similarly, among the 1354 probesets showing expression changes on the axonal side of Smn knockdown motoneurons, 29 probesets $(2.1 \%)$ represented U12-type intron genes. Thus, U12type transcripts are not particularly susceptible to Smn knockdown with respect to levels and presence in the axonal compartment.

\section{DISCUSSION}

In this study, we have optimized techniques for compartmentalized cultures of motoneurons to examine their axonal transcriptome. Our data indicate that, in motoneurons, the mRNA composition of axons is highly similar to the somatodendritic part. Despite the similarity in transcript abundance in both compartments, axons are particularly enriched for transcripts related to protein synthesis and energy production. This finding is in accordance with two previous studies, one investigating axonal mRNAs in embryonic DRG neurons 
A

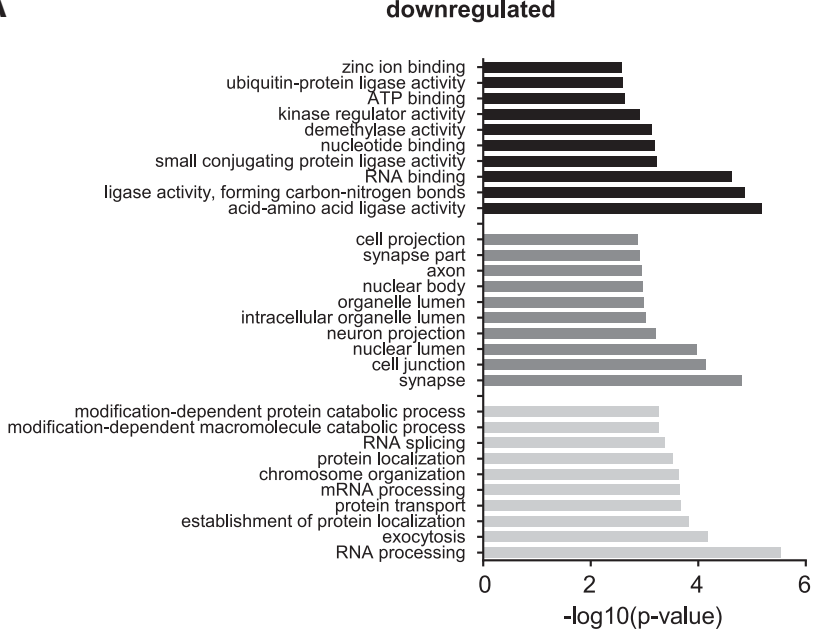

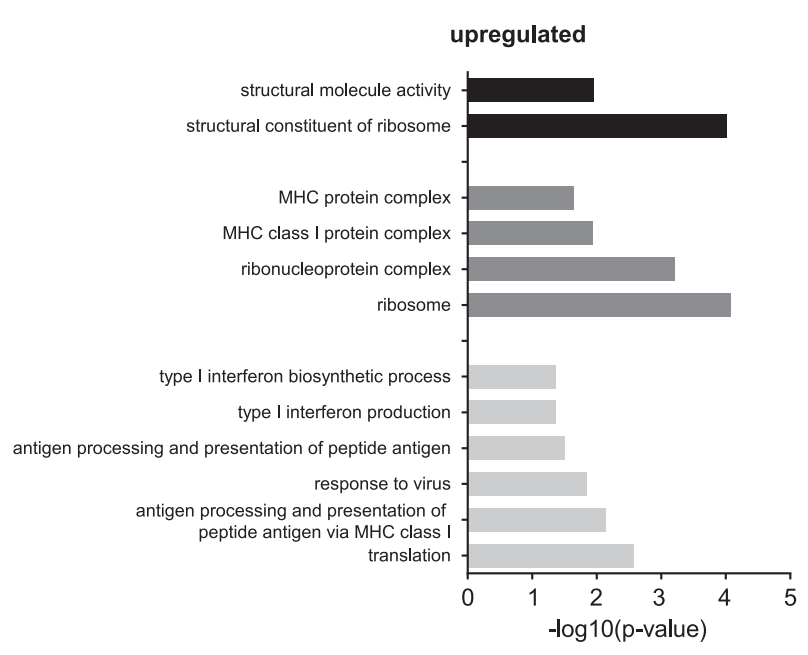

cellular component biological process
B

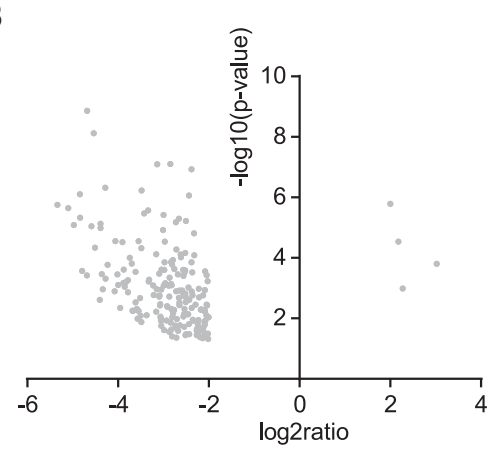

C

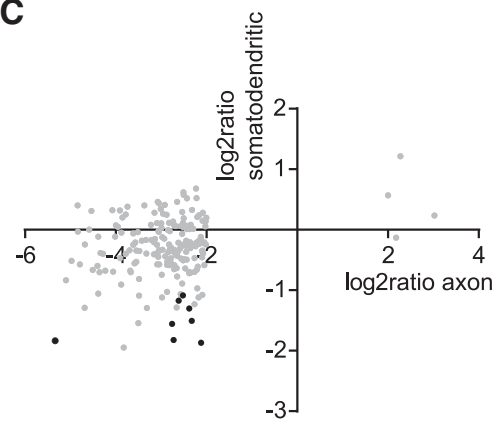

\begin{tabular}{l|l|c|c} 
AffymetrixIDs & Symbol & Ratio soma & Ratio axon \\
\hline 1439410_x_at & SIc25a39 & 0.41 & 0.19 \\
1456177_x_at & Zfp706 & 0.28 & 0.15 \\
1456176_x_at & SIc25a39 & 0.35 & 0.20 \\
1417710_at & Mett19 & 0.34 & 0.15 \\
1451628_a_at & Ank3 & 0.27 & 0.23 \\
1434582_at & Erc2 & 0.28 & 0.02 \\
1455358_at & Rbfox1 & 0.44 & 0.16 \\
1452997_at & 2610005L07Rik & 0.47 & 0.17
\end{tabular}

D

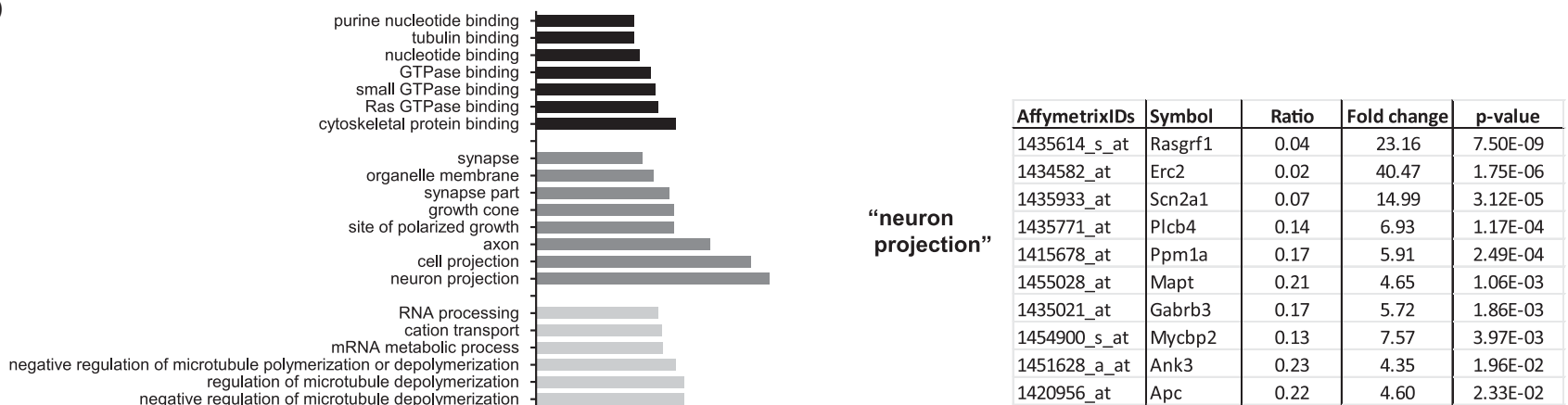
regulation of microtubule depolymerization ulation of microtubule depolymerization phosphoinositide-mediated signaling RNA splicing metal ion transport

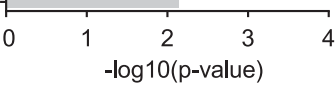
1420956_at Apc 2.33E-02

molecular function

cellular component

biological process

FIGURE 5. Analysis of transcript level changes of axonal compartments of Smn knockdown motoneuron cultures. ( $A$ ) GO term analysis of transcripts down-regulated or up-regulated in response to Smn knockdown $\left(P<0.05\right.$ and $\mid \log _{2}$ ratio $\left.\mid>2\right)$. (B) Volcano plot of 195 microarray probesets with an average expression $>10$ in wild-type and control axons and which are deregulated upon Smn knockdown $\left(P<0.05\right.$ and $\mid \log _{2}$ ratio $\left.\mid>2\right)$. $(C)$ Transcript level changes of the 195 transcripts in $B$ in the axonal and somatodendritic compartments of Smn-deficient motoneurons. Data points marked in black indicate a $P$-value $<0.05$ in the somatodendritic compartment. $(D)$ GO term analysis of the 195 genes described in $B$. The table lists individual probesets changed in axons upon Smn knockdown that are contained in the GO term "neuron projection." 

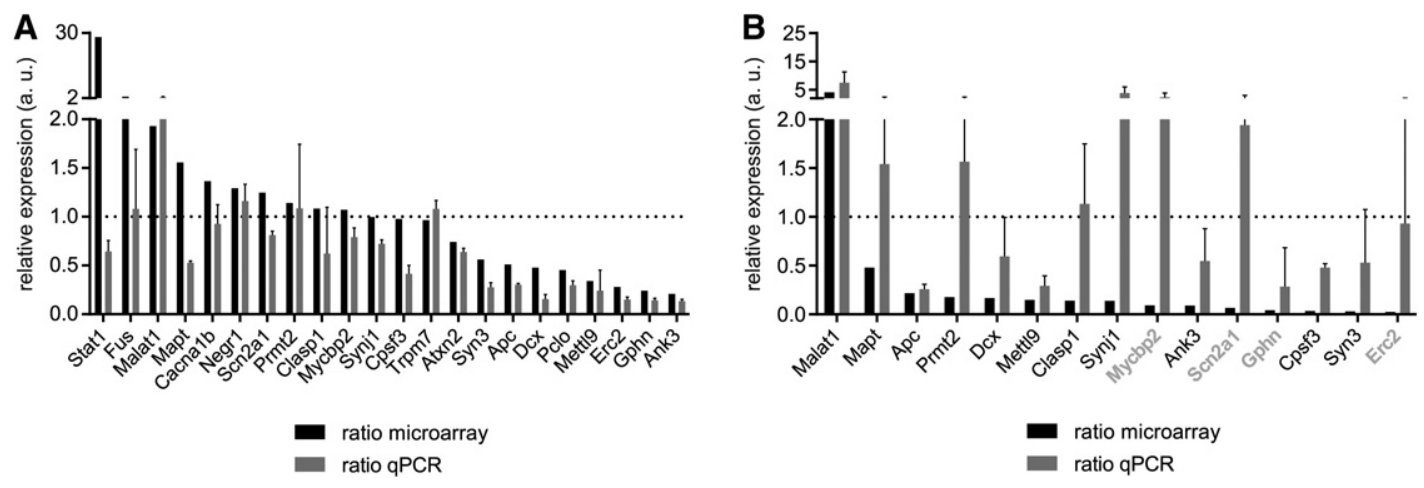

FIGURE 6. Validation of microarray predictions by quantitative PCR for $(A)$ somatodendritic and $(B)$ axonal transcripts. Axonal genes shown in light gray in $B$ have average crossing points $>30$ in the wild-type samples.

(Gumy et al. 2011), the other examining naive mature and regenerating cortical and hippocampal neurons in microfluidic chambers (Taylor et al. 2009). Both studies similarly report an axonal enrichment in transcripts related to protein synthesis and energy production, most likely reflecting the increased energy demand of growing motor axons to facilitate localized protein production.

Following knockdown of Smn, we found a large number of transcripts down-regulated in axons after 7 DIV. Despite being functionally diverse, the down-regulated transcripts were enriched for biological processes related to RNA processing and encode proteins located in neuron projections including axons and growth cones. Among the validated down-regulated mRNAs in the axonal compartment, many are implicated in axon outgrowth and synapse formation. For example, Apc is known to regulate axon arborization and cytoskeletal organization (Chen et al. 2011), whereas Dcx seems to play an important role in the regulation of the actin structure in developing neurons as well as neural migration and outgrowth (Deuel et al. 2006; Fu et al. 2013). Furthermore, Cpsf3 and Syn3 are involved in synapse and axon development as well as neurotransmitter release (Feng et al. 2002; Van et al. 2010) and Ank3 has recently been found to mediate transport of voltage-gated $\mathrm{Na}^{+}$channels into axons (Barry et al. 2014). Variations in these transcripts could explain why altered transmission of action potentials and defects in presynaptic excitability are a prominent feature in Smn-deficient motoneurons (Jablonka et al. 2007; Kong et al. 2009; Ruiz et al. 2010) and could potentially contribute to functional deficits in neurotransmitter release at neuromuscular endplates (Kong et al. 2009; Ruiz et al. 2010).

Another interesting finding in our study was the up-regulation of MHC class I transcripts in both the somatodendritic and axonal compartment of Smn knockdown motoneurons. It is already known that axotomy, ventral-horn root avulsion, viral infection, or cytokines increase MHC I expression in motoneurons (Boulanger and Shatz 2004). More recently, it has also been shown that motoneurons of C57SOD1 ${ }^{\text {G93A }}$ mice, a model for ALS, display up-regulation of
MHC class I genes at the onset of disease (Nardo et al. 2013). These findings may suggest a potential neuroprotective function of MHC class I up-regulation. In line with this notion, previous studies have shown the importance of MHC class I overexpression for axonal regeneration and for the stability of neuromuscular junctions after axonal damage (Oliveira et al. 2004; Thams et al. 2009). Furthermore, MHC class I expression seems to be important for the refinement of synapse formation and plasticity in the visual system and the hippocampus (Corriveau et al. 1998; Huh et al. 2000; Boulanger and Shatz 2004; Shatz 2009). Yet an important point is the role of neural activity in regulating MHC class I expression. It has been shown that electrically active neurons in culture are devoid of MHC class I expression, whereas inhibition of their spontaneous electrical currents with interferon- $\gamma$ and tetrodotoxin (TTX) induces MHC class I expression including $\beta_{2}$-microglobulin (Neumann et al. 1995), although some later in vivo experiments reveal a dramatic down-regulation of MHC class I expression after TTX treatment (Corriveau et al. 1998). Smn-deficient motoneurons cultured from a mouse model of SMA have been shown to exhibit reduced spontaneous activity in axons and growth cones at 4 DIV (Jablonka et al. 2007). Thus, the increase in MHC class I gene expression could be a consequence of defects in electrical activity, and enhanced MHC I expression could contribute to reactions of nonneuronal cells that are involved in synaptic and axonal breakdown.

On the somatodendritic side of Smn-deficient motoneurons a large number of transcripts were up- or down-regulated relative to controls. Even though this finding is in agreement with the essential role of SMN in multiple aspects of RNA processing, our result is in contrast to previous microarray and RNA-seq analyses detecting only small numbers of transcriptome changes in presymptomatic spinal cords or motoneurons, respectively, of SMA mouse models (Baumer et al. 2009; Murray et al. 2010; Zhang et al. 2013). This discrepancy might reflect differences both in the remaining Smn levels as well as in the progression of the molecular defects. Nevertheless, we noticed that despite deregulation of a 
substantial number of transcripts in both the somatodendritic and axonal compartments of Smn-deficient motoneurons, minor intron-containing transcripts were not enriched among them. It has previously been shown that loss of Smn affects the levels of individual snRNPs in a tissue-specific manner and particularly lowers the amounts of minor spliceosomal snRNPs including U4atac, U11, and U12 (Gabanella et al. 2007; Zhang et al. 2008; Lotti et al. 2012; Praveen et al. 2012). In accord with this notion, mis-splicing of minor intron transcripts has been detected in Smn-deficient mouse cells and Drosophila smn mutant larvae resulting in a reduction in their mRNA levels (Lotti et al. 2012). Among these transcripts, Stasimon down-regulation has been suggested to underlie the motor circuit dysfunction of smn mutants. However, more recently, evidence has been presented that the splicing alterations of minor introns seen in Drosophila smn mutant larvae could also be a consequence of the developmental arrest of these animals rather than a result of smn deficiency (Praveen et al. 2012; Garcia et al. 2013). In addition, no disruption of minor intron splicing was detected in presymptomatic SMA mice (Zhang et al. 2013). Thus, further experiments are required to resolve whether the nature of splicing defects in Smn-deficient cells and tissues is dependent on the remaining Smn levels or the developmental timepoint at which splicing alterations are monitored.

Conspicuously, we found a number of genes with roles in multiple aspects of RNA splicing to be up-regulated in the somatodendritic compartment of Smn knockdown motoneurons. This finding is of relevance given the role of SMN in the biogenesis of the spliceosomal snRNPs. Among the transcripts up-regulated is the mRNA encoding Casc3 (also known as Btz or MLN51) which is a component of the exon junction complex (EJC) assembled by the spliceosome on exon-exon boundaries after intron excision (Le Hir et al. 2000a,b). Beyond its function in quality control as part of the EJC, Casc3 has recently also been shown to enhance translation efficiency (Chazal et al. 2013). Sf1 and U2af1 are part of the spliceosomal E complex and bind to introns early during the splice cycle to mark the branch point and the $3^{\prime}$ splice site, respectively (Wahl et al. 2009). The SR protein Srsf1 (also known as ASF/SF2) stimulates U1 snRNP binding to the $5^{\prime}$ splice site (Kohtz et al. 1994). We also detected increased expression of the gene encoding the serine/arginine protein kinase Srpk2 which phosphorylates the RS domains of SR proteins (Wang et al. 1998). Initially, Srsf1 was identified as a substrate for Srpk2 (Wang et al. 1998; Koizumi et al. 1999), whereas subsequent experiments suggested that PRP28 as part of the U4/U6-U5 tri-snRNP is the main target for Srpk2 (Mathew et al. 2008). In contrast to Srpk1, which is expressed ubiquitously, Srpk2 exhibits particularly high expression levels in the nervous system suggestive of a neuronspecific function (Wang et al. 1998). Interestingly, Srpk2 was found to be up-regulated in brains of APP/PS1 transgenic mice, a model for Alzheimer's disease (Hong et al. 2012). In that study, knockdown of Srpk2 in APP/PS1 mice alleviat- ed memory deficits and increased synaptic plasticity. Overexpression of Srpk2 in primary neurons led to reduced axon length accompanied by reduced microtubule polymerization due to phosphorylation of Tau. In conclusion, our data indicate an up-regulation of a number of splicing factors. It needs to be determined in future studies whether these alterations contribute to altered splicing activities upon Smn loss, whether they contribute to motoneuron dysfunction or alternatively, whether they signify a mechanism through which affected motoneurons compensate for alterations in the snRNP repertoire. Interestingly, increased expression of the gene encoding the U2 snRNP-specific protein Snrpal has been observed in a number of studies (Baumer et al. 2009; Murray et al. 2010; Zhang et al. 2013). We also observed an up-regulation of Snrpal in the data set of the somatodendritic compartment from Smn-deficient motoneurons which, however, narrowly missed the significance threshold (Supplemental Table S1).

In summary, our data suggest that $S m n$ has profound and distinct effects on the repertoire of somatodendritic as well as axonal mRNAs affecting transcripts with immune functions and roles in splicing, synaptic vesicle release, maintenance of the axonal and presynaptic cytoskeleton, and other biological parameters which are important for motoneuron function. Considering that mRNA processing and transport defects might be causative in other motoneuron diseases such as ALS (Alami et al. 2014), the approach outlined here might also be applicable for investigating axonal transcriptome alterations in other disease contexts.

\section{MATERIALS AND METHODS}

\section{Animals}

CD-1 mice were housed at the animal facilities of the Institute for Clinical Neurobiology at the University Hospital of Wuerzburg. Each experiment was conducted following the regulations on animal protection of the German federal law and of the Association for Assessment and Accreditation of Laboratory Animal Care, in agreement with and under control of the local veterinary authority.

\section{Isolation of primary embryonic mouse motoneurons}

Spinal cords were dissected from E12.5 mouse embryos and, following removal of dorsal root ganglia and meninges, motoneurons were isolated and enriched via p75NTR-panning as described previously (Wiese et al. 2010). Cells were counted and plated in microfluidic chambers as described below.

\section{Knockdown of Smn via lentiviral shRNA in embryonic motoneurons}

For knockdown of Smn, an Smn (5'-GAAGAATGCCACAACTCCC $-3^{\prime}$ ) shRNA sequence (Zhang et al. 2008) was cloned into the pSIHH1 shRNA vector (System Bioscience) and HEK293T cells were used to generate viruses as described previously (Lois et al. 2002; 
Subramanian et al. 2012). Lentiviral knockdown experiments were performed by incubation of motoneurons before plating with either knockdown or control viruses containing empty pSIH-H1 for 10 min at room temperature. Afterward, motoneurons were plated on the somatodendritic side of microfluidic chambers.

\section{Primary motoneuron culture with microfluidic chambers}

Following lentiviral transfection, 1 million motoneurons were plated into one compartment of a microfluidic chamber (Xona Microfluidics, SND 150) precoated with polyornithine and laminin-111 (Invitrogen, 23017-015). To achieve a directed growth of the axons through the microchannels of the microfluidic chamber toward the axonal compartment a BDNF gradient was established by adding this neurotrophic factor at $20 \mathrm{ng} / \mathrm{mL}$ only to the axonal compartment. CNTF ( $5 \mathrm{ng} / \mathrm{mL}$ ) was applied to both compartments for survival. Motoneurons were grown for $7 \mathrm{~d}$ at $37^{\circ} \mathrm{C}$ and $5 \% \mathrm{CO}_{2}$ in neurobasal medium (Invitrogen) containing $500 \mu \mathrm{M}$ GlutaMAX (Invitrogen), 2\% horse serum (Linaris), and 2\% B27 supplement (Invitrogen). Fifty percent of culture medium was exchanged on Day 1 and then every second day.

\section{RNA extraction and linear amplification}

Total RNA of the somatodendritic and axonal compartment was extracted with the Pico Pure RNA Isolation Kit (Arcturus, KIT0204), according to the manufacturer's protocol. Extracted RNA was directly used for linear amplification with the RiboAmp $H S^{\text {Plus }}$ Amplification Kit (Arcturus, KIT0525). Linear amplification was done according to the manufacturer's protocol with labeling of antisense RNA after two rounds of amplification. The biotin-labeled antisense RNA was then hybridized to a microarray chip (Affymetrix Gene Chip Mouse Genome 4302.0 Array, 900496).

\section{Microarray analysis}

Data were analyzed using different R/Bioconductor modules (www. bioconductor.org). Resulting signal intensities were normalized by quantile normalization (Bolstad et al. 2003), differentially expressed genes were selected by the bioconductor package Limma (Smyth 2004). Quality as well as comparability of the data sets was tested by density plot and RNA degradation plot. For functional clustering the Database for Annotation, Visualization and Integrated Discovery (DAVID, http://david.abcc.ncifcrf.gov/home.jsp) was used (da Huang et al. 2009).

\section{Validation of microarray predictions by quantitative real-time PCR}

RNA extracted from the axonal and somatodendritic compartments of wild-type and Smn knockdown motoneurons was linearly amplified for one round using the RiboAmp HS ${ }^{\text {Plus }}$ Amplification Kit and reverse transcribed. The cDNA was diluted 1:10 in water and subsequently used for quantitative real-time PCR with the Luminaris HiGreen qPCR Master Mix (Thermo Scientific) on a Lightcycler
1.5 (Roche). Primer sequences are listed in Supplemental Table S18, Gapdh was used for normalization of cDNA levels between samples.

\section{DATA DEPOSITION}

The microarray data discussed in this publication have been deposited in NCBI's Gene Expression Omnibus (Edgar et al. 2002) and are accessible through GEO Series accession number GSE59506.

\section{SUPPLEMENTAL MATERIAL}

Supplemental material is available for this article.

\section{ACKNOWLEDGMENTS}

This work was supported by the European Community's Health Seventh Framework Programme under grant agreement 259867 (EuroMOTOR), and the German Government (BMBF) funded Motoneuron Disease Network, The Sobek Foundation, and the Hermann und Lilly Schilling-Stiftung im Stifterverband der Deutschen Industrie.

Received July 18, 2014; accepted August 22, 2014.

\section{REFERENCES}

Alami NH, Smith RB, Carrasco MA, Williams LA, Winborn CS, Han SS, Kiskinis E, Winborn B, Freibaum BD, Kanagaraj A, et al. 2014. Axonal transport of TDP-43 mRNA granules is impaired by ALScausing mutations. Neuron 81: 536-543.

Alioto TS. 2007. U12DB: a database of orthologous U12-type spliceosomal introns. Nucleic Acids Res 35: D110-D115.

Andreassi C, Zimmermann C, Mitter R, Fusco S, De VS, Saiardi A, Riccio A. 2010. An NGF-responsive element targets myo-inositol monophosphatase-1 mRNA to sympathetic neuron axons. Nat Neurosci 13: 291-301.

Barry J, Gu Y, Jukkola P, O’Neill B, Gu H, Mohler PJ, Rajamani KT, Gu C. 2014. Ankyrin-G directly binds to kinesin-1 to transport voltage-gated $\mathrm{Na}^{+}$channels into axons. Dev Cell 28: 117-131.

Battle DJ, Kasim M, Yong J, Lotti F, Lau CK, Mouaikel J, Zhang Z, Han K, Wan L, Dreyfuss G. 2006. The SMN complex: an assembly machine for RNPs. Cold Spring Harb Symp Quant Biol 71: 313-320.

Baumer D, Lee S, Nicholson G, Davies JL, Parkinson NJ, Murray LM, Gillingwater TH, Ansorge O, Davies KE, Talbot K. 2009. Alternative splicing events are a late feature of pathology in a mouse model of spinal muscular atrophy. PLoS Genet 5: e1000773.

Bolstad BM, Irizarry RA, Astrand M, Speed TP. 2003. A comparison of normalization methods for high density oligonucleotide array data based on variance and bias. Bioinformatics 19: 185-193.

Boulanger LM, Shatz CJ. 2004. Immune signalling in neural development, synaptic plasticity and disease. Nat Rev Neurosci 5: 521-531.

Burghes AH, Beattie CE. 2009. Spinal muscular atrophy: Why do low levels of survival motor neuron protein make motor neurons sick? Nat Rev Neurosci 10: 597-609.

Chari A, Golas MM, Klingenhager M, Neuenkirchen N, Sander B, Englbrecht C, Sickmann A, Stark H, Fischer U. 2008. An assembly chaperone collaborates with the SMN complex to generate spliceosomal SnRNPs. Cell 135: 497-509.

Chazal PE, Daguenet E, Wendling C, Ulryck N, Tomasetto C, Sargueil B, Le HH. 2013. EJC core component MLN51 interacts with eIF3 and activates translation. Proc Natl Acad Sci 110: 5903-5908. 
Chen Y, Tian X, Kim WY, Snider WD. 2011. Adenomatous polyposis coli regulates axon arborization and cytoskeleton organization via its N-terminus. PLoS One 6: e24335.

Corriveau RA, Huh GS, Shatz CJ. 1998. Regulation of class I MHC gene expression in the developing and mature CNS by neural activity. Neuron 21: 505-520.

da Huang W, Sherman BT, Lempicki RA. 2009. Systematic and integrative analysis of large gene lists using DAVID bioinformatics resources. Nat Protoc 4: 44-57.

Deuel TA, Liu JS, Corbo JC, Yoo SY, Rorke-Adams LB, Walsh CA. 2006. Genetic interactions between doublecortin and doublecortin-like kinase in neuronal migration and axon outgrowth. Neuron 49: 41-53.

Edgar R, Domrachev M, Lash AE. 2002. Gene Expression Omnibus: NCBI gene expression and hybridization array data repository. Nucleic Acids Res 30: 207-210.

Fallini C, Zhang H, Su Y, Silani V, Singer RH, Rossoll W, Bassell GJ. 2011. The survival of motor neuron (SMN) protein interacts with the mRNA-binding protein $\mathrm{HuD}$ and regulates localization of poly(A) mRNA in primary motor neuron axons. J Neurosci 31: 3914-3925.

Fallini C, Rouanet JP, Donlin-Asp PG, Guo P, Zhang H, Singer RH, Rossoll W, Bassell GJ. 2013. Dynamics of survival of motor neuron $(\mathrm{SMN})$ protein interaction with the mRNA-binding protein IMP1 facilitates its trafficking into motor neuron axons. Dev Neurobiol 74: 319-332.

Feng J, Chi P, Blanpied TA, Xu Y, Magarinos AM, Ferreira A, Takahashi RH, Kao HT, McEwen BS, Ryan TA, et al. 2002. Regulation of neurotransmitter release by synapsin III. J Neurosci 22: $4372-4380$.

Fischer U, Liu Q, Dreyfuss G. 1997. The SMN-SIP1 complex has an essential role in spliceosomal snRNP biogenesis. Cell 90: 1023-1029.

Fu X, Brown KJ, Yap CC, Winckler B, Jaiswal JK, Liu JS. 2013. Doublecortin (Dcx) family proteins regulate filamentous actin structure in developing neurons. J Neurosci 33: 709-721.

Gabanella F, Butchbach ME, Saieva L, Carissimi C, Burghes AH, Pellizzoni L. 2007. Ribonucleoprotein assembly defects correlate with spinal muscular atrophy severity and preferentially affect a subset of spliceosomal snRNPs. PLoS One 2: e921.

Garcia EL, Lu Z, Meers MP, Praveen K, Matera AG. 2013. Developmental arrest of Drosophila survival motor neuron (Smn) mutants accounts for differences in expression of minor intron-containing genes. RNA 19: 1510-1516.

Glinka M, Herrmann T, Funk N, Havlicek S, Rossoll W, Winkler C, Sendtner M. 2010. The heterogeneous nuclear ribonucleoprotein$\mathrm{R}$ is necessary for axonal $\beta$-actin mRNA translocation in spinal motor neurons. Hum Mol Genet 19: 1951-1966.

Gumy LF, Yeo GS, Tung YC, Zivraj KH, Willis D, Coppola G, Lam BY, Twiss JL, Holt CE, Fawcett JW. 2011. Transcriptome analysis of embryonic and adult sensory axons reveals changes in mRNA repertoire localization. RNA 17: 85-98.

Hengst U, Deglincerti A, Kim HJ, Jeon NL, Jaffrey SR. 2009. Axonal elongation triggered by stimulus-induced local translation of a polarity complex protein. Nat Cell Biol 11: 1024-1030.

Hong Y, Chan CB, Kwon IS, Li X, Song M, Lee HP, Liu X, Sompol P, Jin $P$, Lee HG, et al. 2012. SRPK2 phosphorylates $\tau$ and mediates the cognitive defects in Alzheimer's disease. J Neurosci 32: $17262-17272$.

Huh GS, Boulanger LM, Du H, Riquelme PA, Brotz TM, Shatz CJ. 2000. Functional requirement for class I MHC in CNS development and plasticity. Science 290: 2155-2159.

Jablonka S, Beck M, Lechner BD, Mayer C, Sendtner M. 2007. Defective $\mathrm{Ca}^{2+}$ channel clustering in axon terminals disturbs excitability in motoneurons in spinal muscular atrophy. J Cell Biol 179: 139-149.

Kariya S, Park GH, Maeno-Hikichi Y, Leykekhman O, Lutz C, Arkovitz MS, Landmesser LT, Monani UR. 2008. Reduced SMN protein impairs maturation of the neuromuscular junctions in mouse models of spinal muscular atrophy. Hum Mol Genet 17: 2552-2569.

Kohtz JD, Jamison SF, Will CL, Zuo P, Luhrmann R, Garcia-Blanco MA, Manley JL. 1994. Protein-protein interactions and 5'-splice-site recognition in mammalian mRNA precursors. Nature 368: 119-124.
Koizumi J, Okamoto Y, Onogi H, Mayeda A, Krainer AR, Hagiwara M. 1999. The subcellular localization of SF2/ASF is regulated by direct interaction with SR protein kinases (SRPKs). J Biol Chem 274: $11125-11131$

Kolb SJ, Battle DJ, Dreyfuss G. 2007. Molecular functions of the SMN complex. J Child Neurol 22: 990-994.

Kong L, Wang X, Choe DW, Polley M, Burnett BG, Bosch-Marce M, Griffin JW, Rich MM, Sumner CJ. 2009. Impaired synaptic vesicle release and immaturity of neuromuscular junctions in spinal muscular atrophy mice. J Neurosci 29: 842-851.

Lecuyer E, Yoshida H, Parthasarathy N, Alm C, Babak T, Cerovina T, Hughes TR, Tomancak P, Krause HM. 2007. Global analysis of mRNA localization reveals a prominent role in organizing cellular architecture and function. Cell 131: 174-187.

Lefebvre S, Burglen L, Reboullet S, Clermont O, Burlet P, Viollet L, Benichou B, Cruaud C, Millasseau P, Zeviani M, et al. 1995. Identification and characterization of a spinal muscular atrophy-determining gene. Cell 80: 155-165.

Le Hir H, Izaurralde E, Maquat LE, Moore MJ. 2000a. The spliceosome deposits multiple proteins 20-24 nucleotides upstream of mRNA exon-exon junctions. EMBO J 19: 6860-6869.

Le Hir H, Moore MJ, Maquat LE. 2000b. Pre-mRNA splicing alters mRNP composition: evidence for stable association of proteins at exon-exon junctions. Genes Dev 14: 1098-1108.

Li DK, Tisdale S, Lotti F, Pellizzoni L. 2014. SMN control of RNP assembly: from post-transcriptional gene regulation to motor neuron disease. Semin Cell Dev Biol 32C: 22-29.

Lin AC, Holt CE. 2008. Function and regulation of local axonal translation. Curr Opin Neurobiol 18: 60-68.

Liu Q, Fischer U, Wang F, Dreyfuss G. 1997. The spinal muscular atrophy disease gene product, SMN, and its associated protein SIP1 are in a complex with spliceosomal snRNP proteins. Cell 90: 1013-1021.

Lois C, Hong EJ, Pease S, Brown EJ, Baltimore D. 2002. Germline transmission and tissue-specific expression of transgenes delivered by lentiviral vectors. Science 295: 868-872.

Lotti F, Imlach WL, Saieva L, Beck ES, Hao le T, Li DK, Jiao W, Mentis GZ, Beattie CE, McCabe BD, et al. 2012. An SMN-dependent U12 splicing event essential for motor circuit function. Cell 151: $440-454$.

Mathew R, Hartmuth K, Mohlmann S, Urlaub H, Ficner R, Luhrmann R. 2008. Phosphorylation of human PRP28 by SRPK2 is required for integration of the U4/U6-U5 tri-snRNP into the spliceosome. Nat Struct Mol Biol 15: 435-443.

McGovern VL, Gavrilina TO, Beattie CE, Burghes AH. 2008. Embryonic motor axon development in the severe SMA mouse. Hum Mol Genet 17: 2900-2909.

McWhorter ML, Monani UR, Burghes AH, Beattie CE. 2003 Knockdown of the survival motor neuron (Smn) protein in zebrafish causes defects in motor axon outgrowth and pathfinding. J Cell Biol 162: 919-931.

Mishra VN, Kalita J, Kesari A, Mitta B, Shankar SK, Misra UK. 2004. A clinical and genetic study of spinal muscular atrophy. Electromyogr Clin Neurophysiol 44: 307-312.

Monani UR, Sendtner M, Coovert DD, Parsons DW, Andreassi C, Le TT, Jablonka S, Schrank B, Rossoll W, Prior TW, et al. 2000 . The human centromeric survival motor neuron gene (SMN2) rescues embryonic lethality in $\operatorname{Smn}(-/-)$ mice and results in a mouse with spinal muscular atrophy. Hum Mol Genet 9: 333-339.

Murray LM, Comley LH, Thomson D, Parkinson N, Talbot K, Gillingwater TH. 2008. Selective vulnerability of motor neurons and dissociation of pre- and post-synaptic pathology at the neuromuscular junction in mouse models of spinal muscular atrophy. Hum Mol Genet 17: 949-962.

Murray LM, Lee S, Baumer D, Parson SH, Talbot K, Gillingwater TH. 2010. Pre-symptomatic development of lower motor neuron connectivity in a mouse model of severe spinal muscular atrophy. Hum Mol Genet 19: 420-433.

Nardo G, Iennaco R, Fusi N, Heath PR, Marino M, Trolese MC, Ferraiuolo L, Lawrence N, Shaw PJ, Bendotti C. 2013. 
Transcriptomic indices of fast and slow disease progression in two mouse models of amyotrophic lateral sclerosis. Brain 136: $3305-3332$.

Neumann H, Cavalie A, Jenne DE, Wekerle H. 1995. Induction of MHC class I genes in neurons. Science 269: 549-552.

Oliveira AL, Thams S, Lidman O, Piehl F, Hokfelt T, Karre K, Linda H, Cullheim S. 2004. A role for MHC class I molecules in synaptic plasticity and regeneration of neurons after axotomy. Proc Natl Acad Sci 101: 17843-17848.

Piazzon N, Rage F, Schlotter F, Moine H, Branlant C, Massenet S. 2008. In vitro and in cellulo evidences for association of the survival of motor neuron complex with the fragile $\mathrm{X}$ mental retardation protein. $J$ Biol Chem 283: 5598-5610.

Praveen K, Wen Y, Matera AG. 2012. A Drosophila model of spinal muscular atrophy uncouples snRNP biogenesis functions of survival motor neuron from locomotion and viability defects. Cell Rep 1: 624-631.

Rossoll W, Kroning AK, Ohndorf UM, Steegborn C, Jablonka S, Sendtner M. 2002. Specific interaction of Smn, the spinal muscular atrophy determining gene product, with hnRNP-R and gry-rbp/ hnRNP-Q: a role for Smn in RNA processing in motor axons? Hum Mol Genet 11: 93-105.

Rossoll W, Jablonka S, Andreassi C, Kroning AK, Karle K, Monani UR, Sendtner M. 2003. Smn, the spinal muscular atrophy-determining gene product, modulates axon growth and localization of $\beta$-actin mRNA in growth cones of motoneurons. J Cell Biol 163: 801-812.

Ruiz R, Casanas JJ, Torres-Benito L, Cano R, Tabares L. 2010. Altered intracellular $\mathrm{Ca}^{2+}$ homeostasis in nerve terminals of severe spinal muscular atrophy mice. J Neurosci 30: 849-857.

Shatz CJ. 2009. MHC class I: an unexpected role in neuronal plasticity. Neuron 64: 40-45.

Smyth GK. 2004. Linear models and empirical Bayes methods for assessing differential expression in microarray experiments. Stat Appl Genet Mol Biol 3: Article3.

Subramanian N, Wetzel A, Dombert B, Yadav P, Havlicek S, Jablonka S, Nassar MA, Blum R, Sendtner M. 2012. Role of $\mathrm{Na}_{\mathrm{v}} 1.9$ in activitydependent axon growth in motoneurons. Hum Mol Genet 21: 3655-3667.

Swoboda KJ, Prior TW, Scott CB, McNaught TP, Wride MC, Reyna SP, Bromberg MB. 2005. Natural history of denervation in SMA: relation to age, SMN2 copy number, and function. Ann Neurol 57: 704-712.

Taylor AM, Berchtold NC, Perreau VM, Tu CH, Li JN, Cotman CW. 2009. Axonal mRNA in uninjured and regenerating cortical mammalian axons. J Neurosci 29: 4697-4707.
Thams S, Brodin P, Plantman S, Saxelin R, Karre K, Cullheim S. 2009. Classical major histocompatibility complex class I molecules in motoneurons: new actors at the neuromuscular junction. J Neurosci 29: 13503-13515.

Tsuiji H, Iguchi Y, Furuya A, Kataoka A, Hatsuta H, Atsuta N, Tanaka F, Hashizume Y, Akatsu H, Murayama S, et al. 2013. Spliceosome integrity is defective in the motor neuron diseases ALS and SMA. EMBO Mol Med 5: 221-234.

Van EH, Dai Y, Qi Y, Goncharov A, Jin Y. 2010. Nuclear pre-mRNA 3'end processing regulates synapse and axon development in C. elegans. Development 137: 2237-2250.

Vogelaar CF, Gervasi NM, Gumy LF, Story DJ, Raha-Chowdhury R, Leung KM, Holt CE, Fawcett JW. 2009. Axonal mRNAs: characterisation and role in the growth and regeneration of dorsal root ganglion axons and growth cones. Mol Cell Neurosci 42: 102115.

Wahl MC, Will CL, Luhrmann R. 2009. The spliceosome: design principles of a dynamic RNP machine. Cell 136: 701-718.

Wang HY, Lin W, Dyck JA, Yeakley JM, Songyang Z, Cantley LC, Fu XD. 1998. SRPK2: a differentially expressed SR protein-specific kinase involved in mediating the interaction and localization of pre-mRNA splicing factors in mammalian cells. J Cell Biol 140: 737-750.

Wang IF, Reddy NM, Shen CK. 2002. Higher order arrangement of the eukaryotic nuclear bodies. Proc Natl Acad Sci 99: 13583-13588.

Wiese S, Herrmann T, Drepper C, Jablonka S, Funk N, Klausmeyer A, Rogers ML, Rush R, Sendtner M. 2010. Isolation and enrichment of embryonic mouse motoneurons from the lumbar spinal cord of individual mouse embryos. Nat Protoc 5: 31-38.

Yamazaki T, Chen S, Yu Y, Yan B, Haertlein TC, Carrasco MA, Tapia JC, Zhai B, Das R, Lalancette-Hebert M, et al. 2012. FUS-SMN protein interactions link the motor neuron diseases ALS and SMA. Cell Rep 2: 799-806.

Zhang HL, Pan F, Hong D, Shenoy SM, Singer RH, Bassell GJ. 2003. Active transport of the survival motor neuron protein and the role of exon-7 in cytoplasmic localization. J Neurosci 23: 66276637.

Zhang Z, Lotti F, Dittmar K, Younis I, Wan L, Kasim M, Dreyfuss G. 2008. SMN deficiency causes tissue-specific perturbations in the repertoire of snRNAs and widespread defects in splicing. Cell 133: 585-600.

Zhang Z, Pinto AM, Wan L, Wang W, Berg MG, Oliva I, Singh LN, Dengler C, Wei Z, Dreyfuss G. 2013. Dysregulation of synaptogenesis genes antecedes motor neuron pathology in spinal muscular atrophy. Proc Natl Acad Sci 110: 19348-19353. 

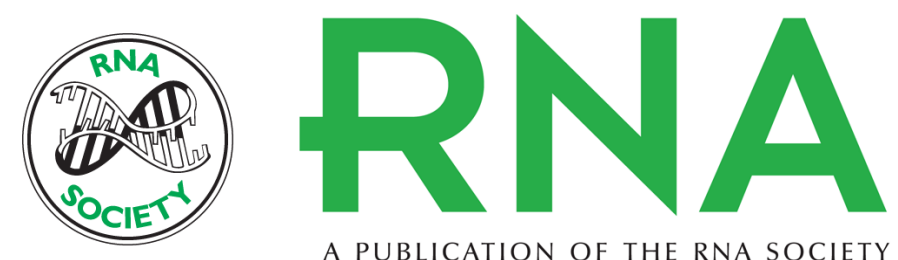

A PUBLICATION OF THE RNA SOCIETY

\section{Subcellular transcriptome alterations in a cell culture model of spinal muscular atrophy point to widespread defects in axonal growth and presynaptic differentiation}

Lena Saal, Michael Briese, Susanne Kneitz, et al.

RNA 2014 20: 1789-1802 originally published online September 22, 2014

Access the most recent version at doi:10.1261/rna.047373.114

Supplemental Material

References

Creative Commons License

Email Alerting Service
http://rnajournal.cshlp.org/content/suppl/2014/09/10/rna.047373.114.DC1

This article cites 75 articles, 29 of which can be accessed free at: http://rnajournal.cshlp.org/content/20/11/1789.full.html\#ref-list-1

This article is distributed exclusively by the RNA Society for the first 12 months after the full-issue publication date (see http://rnajournal.cshlp.org/site/misc/terms.xhtml). After 12 months, it is available under a Creative Commons License (Attribution-NonCommercial 4.0 International), as described at http://creativecommons.org/licenses/by-nc/4.0/.

Receive free email alerts when new articles cite this article - sign up in the box at the top right corner of the article or click here.

\section{|IIIIIII Providing Precise Solutions for} your research.

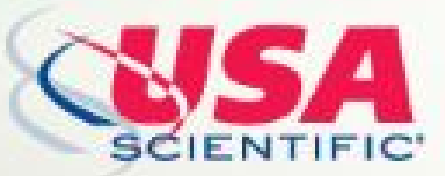

To subscribe to $R N A$ go to:

http://rnajournal.cshlp.org/subscriptions 